\title{
Redes de dutos e transformações espaciais: analogia com carbodutos para armazenamento geológico de $\mathrm{CO}_{2}$
}

\author{
Gabriela Camboim Rockett, João Marcelo Medina Ketzer ${ }^{*}$
}

\section{Resumo}

O transporte dos recursos energéticos fósseis, os quais são essenciais para o desenvolvimento da sociedade atual, é feito predominantemente por redes de dutos. Objetivando avaliar as transformações espaciais decorrentes da implantação de dutos a fim de fazer uma analogia com a construção de "carbodutos" para armazenamento geológico de carbono, foi realizado um estudo de caso da faixa de oleodutos OSCAN (Gravataí/Rio Grande do Sul). Fotografias aéreas, imagens de satélite, idas a campo e softwares de geoprocessamento foram utilizados para conduzir este trabalho. Através de técnicas de sensoriamento remoto, foram constatadas diversas transformações espaciais na área de estudo em função da implantação da dutovia OSCAN, além de re-configurações espaciais decorrentes do processo de desenvolvimento do município ao longo dos anos. Por fim, verificou-se que a implantação de carbodutos é análoga e também transformará a paisagem tanto em escala regional como nacional.

Palavras-chave: Dutos; Transformações espaciais; Sensoriamento remoto; Espaço geográfico; Armazenamento geológico de $\mathrm{CO}_{2}$.

\footnotetext{
* CEPAC/PUCRS - Centro de Excelência em Pesquisa e Inovação em Petróleo, Recursos Minerais e Armazenamento de Carbono /Pontifícia Universidade Católica do Rio Grande do Sul (gabriela.rockett@pucrs.br e marcelo.ketzer@pucrs.br).
}

Geosul, Florianópolis, v. 27, n. 53, p 43-61, jan./jun. 2012 
ROCKETT, G.C e KETZER, J.M.M. Redes de dutos e transformações ...

Pipelines and spatial transformations: analogy with $\mathrm{CO}_{2}$ pipelines for $\mathrm{CO}_{2}$ geological storage

\section{Abstract}

Pipelines are the main mean of transport of fossil fuels, which are nowadays essential for the society. This study aimed to evaluate the spatial transformations resulting from pipelines deployment and make an analogy of such transformations in case of $\mathrm{CO}_{2}$ pipelines construction for geological storage of $\mathrm{CO}_{2}$, through a case study of the OSCAN pipeline (Gravataí/Rio Grande do Sul). Aerial photographs, satellite images, field trips and geoprocessing software were used in this study. By means of remote sensing techniques, several spatial transformations were demonstrated in the studied area, in terms of vegetation, agriculture, roads, pipelines, inhabited area and land reconfigurations depending on the deployment of pipeline and city development processes itself over time. Finally, it was verified that the deployment of $\mathrm{CO}_{2}$ pipelines will also transform space in both regional and national scales.

Key words: Pipeline network; Spatial transformations; Remote sensing; Geographic space; $\mathrm{CO}_{2}$ geological storage.

\section{Introdução}

A complexidade do espaço geográfico possibilita múltiplas análises dos diversos sistemas de objetos e ações que o constituem. A dinâmica existente entre os sistemas de ações e objetos produz diversas configurações espaciais, materializando a ação da sociedade espaço. Assim, o espaço geográfico está em permanente processo de (re)configuração.

A introdução de combustíveis fósseis derivados de petróleo em larga escala no Brasil e no mundo no Século XIX, criou necessidade de uma logística de transporte para a movimentação e distribuição dos mesmos. No território nacional, a construção de dutos para a indústria petrolífera teve início na década de 1950, 
ROCKETT, G.C e KETZER, J.M.M. Redes de dutos e transformações ...

sendo que as primeiras obras concentraram-se na região sudeste do país (SANTOS e SILVEIRA, 2001, p.73).

$\mathrm{O}$ uso crescente de combustíveis fósseis desde então, e consequente aumento das emissões antrópicas de gases de efeito estufa na atmosfera acabou por gerar um problema ambiental a nível mundial: o aquecimento global. Diversos estudos têm demonstrado o aumento da temperatura média da Terra desde a Segunda Revolução Industrial (ex. Le Treut et al, 2007, p.101) e, neste contexto, diversas medidas mitigadoras às emissões antrópicas de $\mathrm{CO}_{2}$ (principal gás de efeito estufa) estão sendo propostas em nível mundial. Dentre elas, a Captura e Armazenamento Geológico de $\mathrm{CO}_{2}$ (CCS, do inglês Carbon Capture and Storage) é uma tecnologia promissora e que atualmente está recebendo investimento no Brasil. Neste contexto, torna-se necessário o desenvolvimento de pesquisas nos três grandes componentes desta atividade: captura, transporte e armazenamento. Após a captura do dióxido de carbono nas fontes emissoras, o transporte do mesmo deve ser feito principalmente por dutos (carbodutos), semelhantes aos existentes no território brasileiro atualmente para transporte de gás natural e petróleo, até o local de injeção e armazenamento em meio geológico.

Esta pesquisa pretende avaliar as transformações espaciais decorrentes da implantação de dutos para a indústria do petróleo, através de um estudo de caso, a fim de fazer uma analogia com a implantação de carbodutos, considerando que a atividade de captura e armazenamento de carbono está em desenvolvimento no Brasil.

\section{Paisagem e espaço geográfico}

Desde o Século XIX a paisagem vem sendo discutida visando obter-se uma melhor compreensão das relações sociais e naturais de determinado espaço. Vidal de La Blache definiu o objeto da geografia na perspectiva da paisagem como sendo a relação homem-natureza (MORAES, 1999), possibilitando, assim, 
ROCKETT, G.C e KETZER, J.M.M. Redes de dutos e transformações ...

a observação das mútuas relações entre o homem e o meio natural. Nestas relações mútuas, Schier (2004, p.83) afirma que os limites entre fenômenos naturais e culturais não podem ser estabelecidos, pois os mesmos se interpenetram. No mesmo contexto, Bertrand (2004, p.141), afirma que a paisagem é "o resultado da combinação dinâmica, portanto instável, de elementos físicos, biológicos e antrópicos que [...] fazem da paisagem um conjunto único e indissociável, Em perpétua evolução".

Milton Santos (2008 p.63), numa concepção contemporânea de paisagem, entende que a paisagem é o conjunto de formas as quais, em certo momento, manifestam as heranças que representam as consecutivas relações entre o homem e a natureza. Em outras palavras, a paisagem é interpretada como forma, ou seja, é a expressão materializada do espaço geográfico.

É preciso considerar nesta pesquisa o processo de construção do espaço geográfico, o qual se dá através dos modos de produção, pois é através dele que verifica-se as (re)configurações das paisagens, assim, tornando possível a avaliação desta transformação. Santos, M. (2008, p.104) ainda afirma que a existência da paisagem se dá através das diferentes formas criadas em momentos históricos distintos, e que coexistem no presente. Partindo da idéia de que a paisagem geográfica se constitui a partir do processo dinâmico entre elementos antrópicos, biológicos e físicos, pode-se dizer que todo o meio natural no qual ocorre ou um dia ocorreu interferência humana constitui uma paisagem geográfica.

\section{Dutos: objetos geográficos}

Dentre os diversos objetos geográficos existentes, os objetos chamados técnicos são aqueles definidos como todos os objetos susceptíveis de funcionar "como meio ou como resultado, entre os requisitos de uma atividade técnica" (SERIS, 1994, p. 22 apud SANTOS, M., 2008, p. 38). Santos, M. (2008, p.64) afirma que os objetos técnicos são resultado do trabalho humano, e são dotados de possibilidades funcionais, assim, pode-se inferir que os 
ROCKETT, G.C e KETZER, J.M.M. Redes de dutos e transformações ...

objetos geográficos técnicos que constituem a indústria petrolífera (plataformas, navios, dutos, refinarias, etc.) são objetos técnicos que configuram e re-configuram constantemente o espaço e geográfico.

A produção e o consumo crescentes de combustíveis fósseis forçaram uma (re)organização territorial para atender às necessidades dos diversos componentes do setor produtivo de petróleo em escala mundial e em escala nacional. Este contexto exigiu uma logística de transporte de óleo/gás eficiente, na qual os dutos são de fundamental importância constituindo redes, as quais, segundo Santos, M. (2008, p.262), têm a função de exercer poder de ligação entre pontos (fixos) e passagem de fluxos. Os fluxos ou ações configuram e espaço geográfico e, neste contexto, Owen $(1975$, p.85) afirma que o transporte é um dos fatores importantes em quase todos os aspectos do desenvolvimento sócio-econômico. Verifica-se que a implantação de um objeto técnico que faz a conexão entre dois territórios distintos, atuando como uma rede, gera re-configurações espaciais em diversas escalas. Os dutos, como objetos geográficos de transporte, atuam diretamente como modeladores dos territórios. Em uma análise geográfica, Sousa (2005, p.9) afirma que a territorialidade dos dutos poderá revelar geograficamente o mercado de combustíveis e as relações entre empresas distribuidoras de petróleo.

\section{Redes de dutos e transformações espaciais}

A Resolução $n^{\circ}$ 01/86 do CONAMA aponta diversas atividades modificadoras do meio ambiente que dependem da aprovação do EIA (Estudo de Impacto Ambiental) e RIMA (Relatório de Impacto Ambiental) para sua implantação, e dentre elas encontra-se vias de circulação e transporte (estradas de rodagem, ferrovias, portos, aeroportos, dutovias, linhas de transmissão), que constituem redes, as quais são responsáveis pelos fluxos. Assim, verifica-se que a implantação de obras de engenharia implica em modificações não só na esfera do meio 
ROCKETT, G.C e KETZER, J.M.M. Redes de dutos e transformações ...

físico, mas também no meio biótico e sócio-econômico, e, portanto, re-configuram o espaço geográfico.

Ao longo do traçado de dutovias existe a denominada faixa de servidão, que consiste em uma faixa de segurança que acompanha o percurso dos dutos, delimitando e protegendo o traçado do mesmo. Esta faixa é estabelecida a fim de reduzir os riscos de vazamentos e acidentes, impedir escavações e construções que possam comprometer as instalações ou interromper no funcionamento do sistema, e também para facilitar o acesso em caso de serviços de manutenção. No caso de as dutovias atravessarem terrenos particulares, a faixa é regulamentada para cada terreno particular por meio de escrituras de servidão firmada entre as partes (proprietário da terra/empresa responsável pela dutovia), segundo Santos, A. (2008, informação verbal).

\section{Estudo de caso: oleodutos OSCAN}

Nesta pesquisa a análise das transformações espaciais foi feita a partir do estudo de caso do sistema de oleodutos OsórioCanoas (OSCAN), localizado em sua totalidade no estado do Rio Grande do Sul. O sistema de oleodutos OSCAN faz a conexão entre o Terminal Marítimo Almirante Soares Dutra (TEDUT) quilômetro 0 da faixa de dutos -, localizado em Osório, e a Refinaria Alberto Pasqualini (REFAP) - quilômetro 98 da faixa de dutos -, em Canoas. O sistema de oleodutos atravessa 7 municípios em sua trajetória, predominantemente áreas rurais e terrenos planos.

A área escolhida para este estudo é de $5,23 \mathrm{~km}^{2}$, localiza-se no município de Gravataí e abrange aproximadamente $5,5 \mathrm{~km}$ da faixa de oleodutos OSCAN (entre os quilômetros 82 e 76 da dutovia) e adjacências (Figura 1). $\mathrm{Na}$ área de estudo foram observadas diferenças de cotas no terreno (Figura 2). 
ROCKETT, G.C e KETZER, J.M.M. Redes de dutos e transformações ...

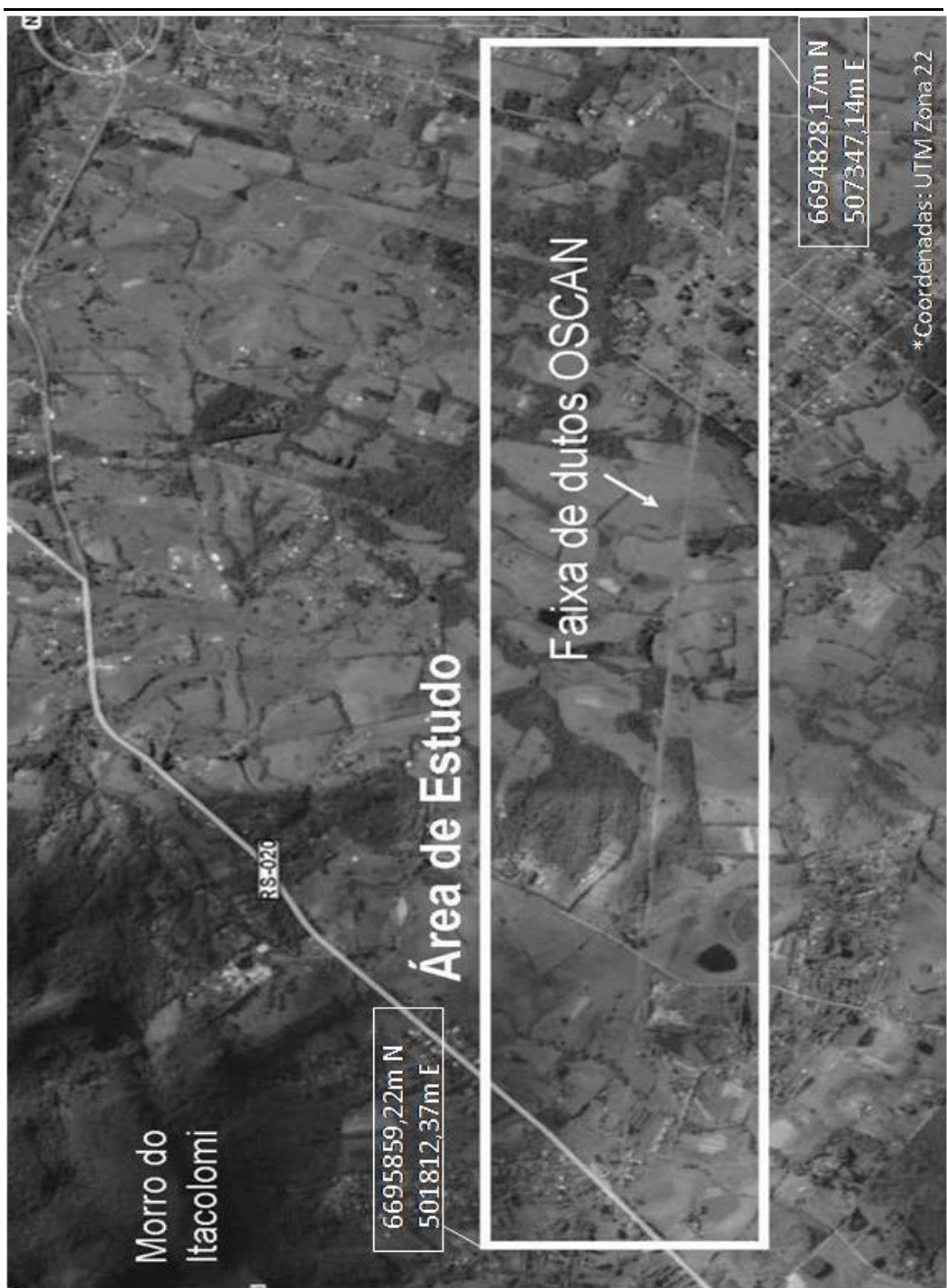

FIGURA 1: Área de estudo: dutovia OSCAN - trecho no município de Gravataí/RS (modificado de Google Earth, 2008) 
ROCKETT, G.C e KETZER, J.M.M. Redes de dutos e transformações ...

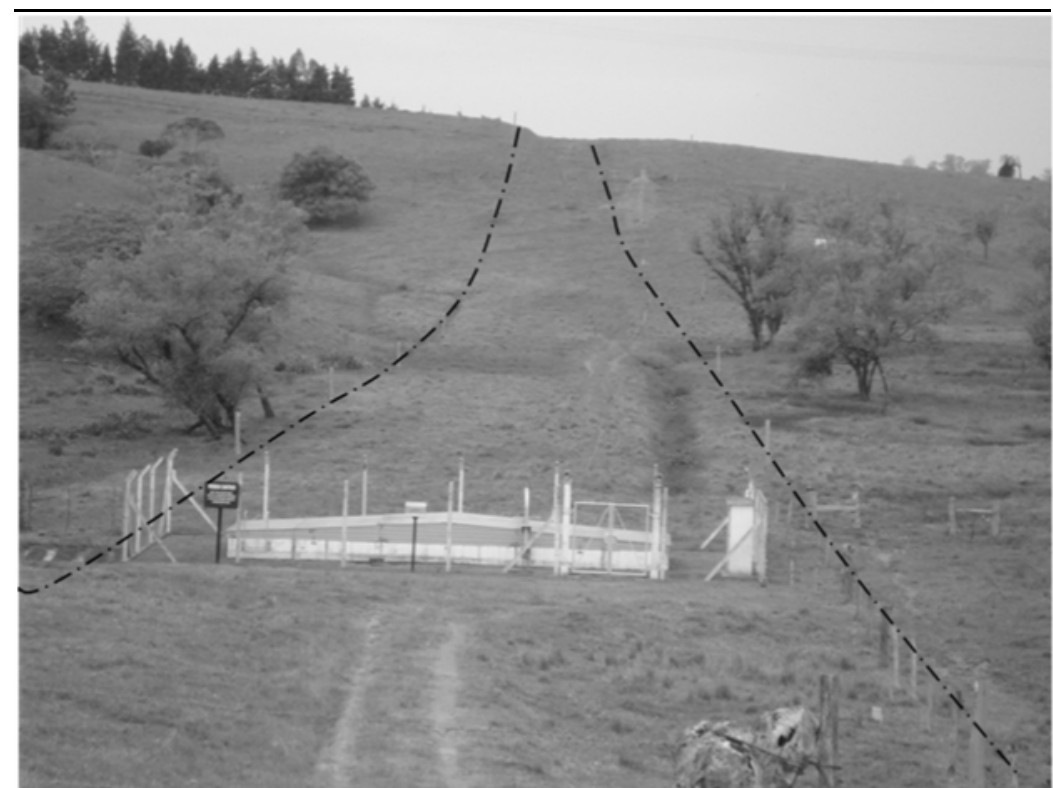

FIGURA 2: Trecho da dutovia OSCAN no município de Gravataí/RS: diferença de cota

O primeiro oleoduto da faixa de dutos Osório-Canoas (OSCAN 16") entrou em operação em 1968, e a implantação da via se deu por meio de imposição do exército (ditadura) e regulamentada por meio de escrituras de servidão de passagem. Um processo indenizatório para os proprietários das terras atingidas pelo empreendimento também foi realizado por parte da Petrobras (SANTOS, A., 2008, informação verbal). As informações sobre a implantação do oleoduto na década de 60 são escassas, visto que a obra é muito antiga e, portanto, não exigia-se estudos prévios à obra como EIA e RIMA na área de implantação. Os registros encontrados sobre a área de estudo em época anterior à implantação da faixa de dutos são fotografias aéreas do ano de 1953 na escala de 1:40.000, as quais serviram de subsídio para a 
ROCKETT, G.C e KETZER, J.M.M. Redes de dutos e transformações ...

caracterização da mesma. Para a caracterização atual foram utilizadas imagens de satélite do ano de 2007.

Foi realizada a fotointerpretação da área de estudo e adjacências para o ano de 1953. Após, as fotografias foram digitalizadas e, através de pontos de referência coletados com GPS em campo, as mesmas foram georreferenciadas em um software de geoprocessamento, onde os elementos da paisagem foram definidos através de vetorização (vegetação, área cultivada, corpos d'água, estradas, solo exposto, etc.). Estes procedimentos possibilitaram a reconstituição dos elementos fixos da paisagem antes da implantação do primeiro oleoduto na região. Para o ano de 2007, foi feito um mosaico georreferenciado de 27 imagens de satélite do Google Earth em escala aproximada de 1:1.500. Foram realizadas visitas à área de estudo para confirmação dos dados, obtenção de coordenadas com GPS e documentação fotográfica. Dados referentes à distribuição fundiária em época anterior à implantação da faixa de dutos foram facilitados pela TRANSPETRO para este trabalho.

As análises realizadas proporcionaram a constatação de alterações que ocorreram no parcelamento do solo, na vegetação, nas edificações, na malha viária e na área destinada à atividade agrícola. As superfícies destas áreas para o ano de 2007 foram estimadas através de software ArcGIS. Ainda, as superfícies das aerofotos de 1953 também foram estimadas, porém, deve-se levar em conta as limitações de análises quantitativas destas. Pode-se visualizar na Tabela 1 a ampliação/retração das superfícies que constituem o uso do solo na área de estudo entre 1953 e 2007.

Análise da configuração territorial atual demonstra o intenso processo de apropriação do homem sobre a natureza ao longo destes 54 anos (1953-2007). Constatou-se que no ano de 1953 a vegetação original correspondia a uma superfície de $1,60 \mathrm{~km}^{2}$, aproximadamente $30,6 \%$ da área de estudo. Em 2007 a mesma cobertura vegetal cobre uma área de $1,06 \mathrm{~km}^{2}$ (aproximadamente $20,3 \%$ da área de estudo), ou seja, houve uma retração de 
ROCKETT, G.C e KETZER, J.M.M. Redes de dutos e transformações ... aproximadamente $33,8 \%$ da área coberta por vegetação original entre os anos de 1953 e 2007.

TABELA 1: Uso do solo na área de estudo nos anos de 1953 e 2007

\begin{tabular}{|c|c|c|}
\hline \multirow{2}{*}{ USO DO SOLO } & \multicolumn{2}{|c|}{ \% sobre a área total } \\
\hline & 1953 & 2008 \\
\hline Vegetação Original & $30,60 \%$ & $20,27 \%$ \\
\hline Área de Uso Agrícola & $30,52 \%$ & $0,76 \%$ \\
\hline Malha Viária & $0,87 \%$ & $3,34 \%$ \\
\hline Rodovia (RS 020, estradas e caminhos) & $0,87 \%$ & $1,10 \%$ \\
\hline Dutovia (oleodutos OSCAN) & $\mathrm{x}$ & $2,24 \%$ \\
\hline Área Habitada & $\mathrm{x}$ & $7,06 \%$ \\
\hline Área total de estudo & \multicolumn{2}{|c|}{$100 \%$} \\
\hline
\end{tabular}

O contexto geo-histórico da área de estudo indica um desenvolvimento significativo no município de Gravataí nas últimas décadas do Século XIX através do cultivo da mandioca, que era exportada para outras porções do território brasileiro (Gravataí, 2010). A partir da interpretação das fotografias aéreas, verificou-se intensa ação antrópica em grande porção da área de estudo na década de 50, sendo indicativa de área cultivada, segundo o padrão verificado no solo. Uma estimativa realizada através de geoprocessamento aponta que 30,5\% da área de estudo era utilizada para agricultura em 1953.

O início da atividade industrial no município de Gravataí data da década de 60 , com a criação do distrito industrial na região (Gravataí, 2010). Neste contexto, a análise da área atualmente comprova uma diminuição de $97 \%$ do uso do solo para fins agrícolas, comparando os anos de 1953 e 2007. Com relação à malha viária, verificou-se que a rodovia estadual RS 020 já fazia parte da paisagem da área de estudo na década de 50, bem como outras estradas e caminhos de chão batido. Em comparação com o ano de 2007, verificou-se uma significativa ampliação da superfície viária na área de estudo, principalmente devido à implantação da dutovia OSCAN na década de 60, bem como a 
ROCKETT, G.C e KETZER, J.M.M. Redes de dutos e transformações ... abertura de novas estradas decorrentes do processo de desenvolvimento da região em questão. Em pouco mais de 50 anos, verificou-se a triplicação da superfície viária da área (atualmente corresponde a $3,34 \%$ da área de estudo), o que explicita o aumento dos fluxos não só em escala local, mas em escala regional devido ao transporte de petróleo e derivados para a Refinaria Alberto Pasqualini, transformando os territórios e a paisagem e reconfigurando o espaço. A transformação espacial área de estudo pode ser visualizada na Figura 3.

Dados referentes ao parcelamento do solo na faixa de dutos OSCAN indicam que a área sofreu re-configurações ao longo do tempo: antigos latifúndios hoje estão distribuídos em porções menores de terras, principalmente em função de partilha de bens entre descendentes das famílias. Entre os quilômetros 76,8 e 77,8 da faixa de dutos OSCAN, na porção leste da área de estudo desta pesquisa, verifica-se no ano de 2007 uma área de 7\% é ocupada por pequenas propriedades $\left(0,37 \mathrm{~km}^{2}\right.$, aproximadamente $7 \%$ da área total), que correspondem ao loteamento Cádiz (Figura 3), no qual a faixa de dutos cruza diversas propriedades.

Nas intersecções com estradas a dutovia está protegida por cercas implantadas pela TRANSPETRO a fim de impedir o acesso de veículos na dutovia. A indicação da existência de faixa de dutos é clara, bem como as sinalizações de área não edificável e de proibição de trânsito de veículos sobre a dutovia nos dois lados da rodovia que intersecciona a mesma. 
ROCKETT, G.C e KETZER, J.M.M. Redes de dutos e transformações ...

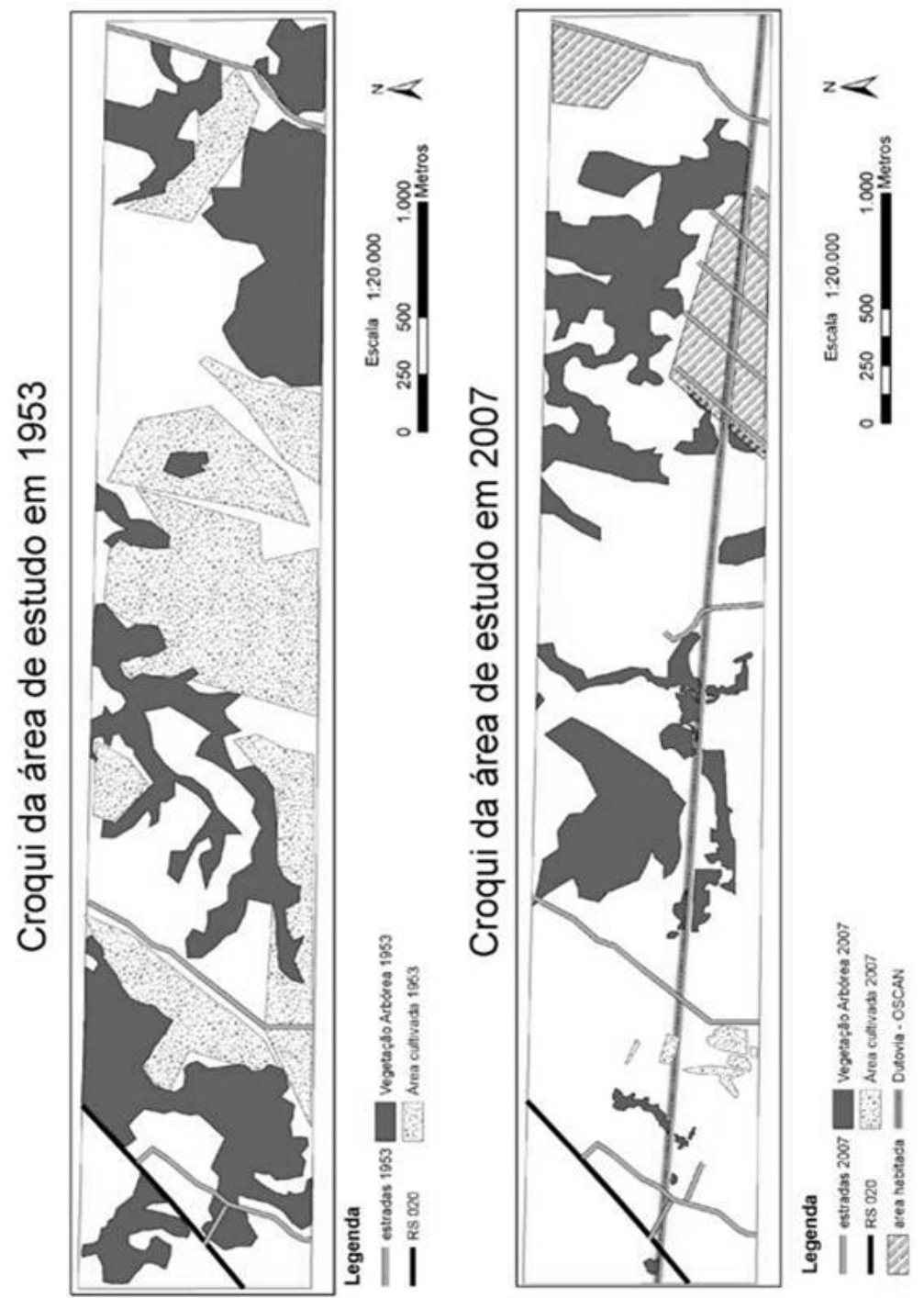

FIGURA 3: Área de estudo nos anos de 1953 e 2007. 
ROCKETT, G.C e KETZER, J.M.M. Redes de dutos e transformações ...

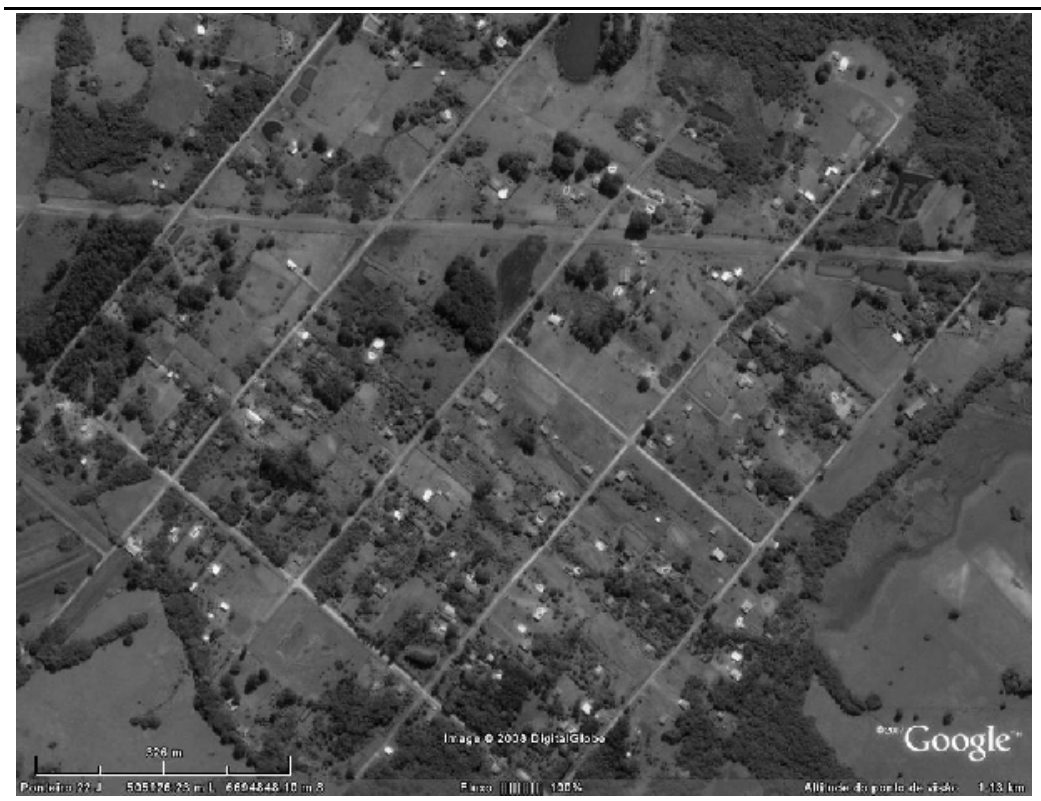

FIGURA 3: Faixa de dutos OSCAN atravessando propriedades do Loteamento Cádiz - Gravataí/RS (modificado de Google Earth, 2008)

\section{Armazenamento geológico de $\mathrm{CO}_{2}$ e carbodutos}

As mudanças climáticas estão entre as questões ambientais de maior repercussão mundial, devido às ocorrências recentes de fenômenos excepcionais no planeta Terra. Diversas medidas estão sendo tomadas e mecanismos vêm sendo adotados para reduzir as emissões de gases de efeito estufa, como a retificação do Protocolo de Quioto, produção de biocombustíveis, produção de energia solar e eólica, entre outros. A atividade denominada Captura e Armazenamento Geológico de $\mathrm{CO}_{2}$, baseada no princípio de "devolver o carbono para o subsolo" (DAVIDSON et al, 2001, p.12; Beecy e Kuuskraa, 2001, p.154) objetiva o aprisionamento do $\mathrm{CO}_{2}$ camadas geológicas favoráveis, os quais possuem a capacidade de reter fluido por milhares de anos. Esta atividade 
ROCKETT, G.C e KETZER, J.M.M. Redes de dutos e transformações ...

envolve, essencialmente, três processos: primeiramente deve ser realizada a captura de dióxido de carbono na fonte emissora estacionária (indústrias, termelétricas, etc.); após, deve ser feito o transporte do $\mathrm{CO}_{2}$ por meio de dutos (os carbodutos) até o local apropriado para então ser realizada a injeção do $\mathrm{CO}_{2}$ no reservatório geológico, onde o mesmo ficará armazenado.

Considerando que o Brasil é um dos maiores emissores de $\mathrm{CO}_{2}$ em escala mundial, a PETROBRAS tem investido em desenvolvimentos de tecnologias visando o seu armazenamento. No âmbito de mudanças climáticas, o investimento em pesquisa nesta área é crescente e diversos estudos relacionados ao sequestro de $\mathrm{CO}_{2}$ estão sendo realizados no Brasil (KETZER et al, 2007; KETZER et al, 2009; Machado et al, 2010, Lima et al, 2011, Rockett et al, 2011). A implantação de carbodutos será necessária no caso do desenvolvimento desta atividade no território nacional para que o $\mathrm{CO}_{2}$ seja transportado da fonte emissora até o local apropriado para o seu armazenamento.

Um fator importante que é considerado quando realizam-se estudos de viabilidade para implantação de novos dutos é a existência ou não de traçados de dutos na região, visto que, segundo Hendriks et al (2004, p.11), os custos podem ser reduzidos quando já existe uma faixa de dutos implantada.

\section{Considerações finais}

A análise espacial realizada nesta pesquisa possibilitou a constatação de diversas re-configurações espaciais na área de estudo. Em escala nacional, verificou-se que o crescimento da indústria do petróleo na segunda metade do Séc. XX gerou a necessidade de redes de distribuição dos produtos e consequentes transformações espaciais e paisagísticas ocorreram no Brasil em função deste contexto.

$\mathrm{Na}$ área de estudo, verificou-se que a implantação da dutovia OSCAN gerou transformações territoriais e uma re-configuração espacial. Com relação à remoção da cobertura vegetal natural para 
ROCKETT, G.C e KETZER, J.M.M. Redes de dutos e transformações ...

a implantação da faixa de dutos verificou-se que não foi muito significativa, comparando-se com a remoção da vegetação para o uso humano, como aconteceu na área do loteamento Cádiz e anteriormente para o uso agrícola. As áreas de uso agrícola, que compreendiam aproximadamente a $30 \%$ da área de estudo, cuja atividade era a principal fonte de desenvolvimento econômico de Gravataí até a primeira metade do Séc. XX, foram reduzidas quando da implantação da dutovia OSCAN, devido à restrições do uso do solo na faixa de dutos. A expansão da malha viária foi muito significativa principalmente em função da dutovia, a qual corresponde à uma superfície de aproximadamente $120.000 \mathrm{~m}^{2}$. A expansão de estradas se deu predominantemente pela ocupação humana em áreas rurais, devido ao crescimento da cidade, para facilitar o acesso nestas áreas. O parcelamento do solo verificado no período, propiciou o surgimento de pequenas propriedades na área de estudo. Neste contexto, verificou-se grande aumento da área habitada.

Considerando que o transporte propicia articulações entre regiões em diferentes escalas, verifica-se que, com a fundação da REFAP (em Canoas) no mesmo ano do início de operação do oleoduto OSCAN 22", o desenvolvimento da indústria de refinaria teve seu início, assim servindo também de articulação com a indústria petroquímica (COPESUL). A formação de redes especializadas de produtos petroquímicos viriam por atender grande parte do Rio Grande do Sul, bem como transformar a paisagem de diversas regiões do Estado.

O presente trabalho, ao diagnosticar as transformações espaciais e paisagísticas na área do oleoduto OSCAN pode servir de analogia para a construção de carbodutos, visto que o processo de implantação da dutovia é o mesmo (havendo variações referentes à questões técnicas, como o material das tubulações, riscos de corrosão em função do produto transportado, etc.). Áreas anteriormente já desapropriadas, onde já existe faixa de dutos instalada, são mais favoráveis para implantação de carbodutos. 
ROCKETT, G.C e KETZER, J.M.M. Redes de dutos e transformações ...

Tendo em vista que toda a ação humana sobre o meio natural modifica a paisagem geográfica, pode-se dizer que não só a construção dos carbodutos, mas este empreendimento (sequestro geológico de carbono) como um todo atuará sobre o espaço geográfico re-configurando a paisagem em diversas escalas. As reorganizações territoriais inerentes de um processo e implantação de uma atividade econômica em certo espaço implicarão em transformações sócio-ambientais, econômicas e no meio físico, sendo estes constituintes do espaço geográfico. A dinâmica espacial envolvendo as diversas atividades da indústria do petróleo em função do transporte (fluxo) é complexa, gerando articulações em diversas escalas. As articulações espaciais geradas pelo conjunto de objetos geográficos implantados da indústria do petróleo re-organizam constantemente a paisagem.

Considerando-se que o contexto afeta a organização espacial, conclui-se que todos os fatores envolvendo a implantação de uma dutovia transformam o espaço em escala local, regional e nacional.

\section{Referências bibliográficas}

BEECY, D. J.; KUUSKRAA, V. A. Status of U.S. geologic carbon sequestration research and technology. Environmental

Geosciences, v. 8, p. 152-159, set. 2001.

BERTRAND, Georges. Paisagem e geografia física global. Esboço metodológico. Revista RA' E GA, Curitiba, n. 8, p. 141-152, 2004. Editora UFPR.

CONAMA - Conselho Nacional do Meio Ambiente. Resolução n ${ }^{\circ}$ 01, de 1986. Diário Oficial [da] República Federativa do Brasil, Brasília, DF, 17 fev. 1986, Seção 1, p. 2548-2549. 
ROCKETT, G.C e KETZER, J.M.M. Redes de dutos e transformações ...

DAVIDSON, J.; FREUD, P.; SMITH, A. Puting carbon back into the ground. IEA Greenhouse Gas R\&D Programme Report, 2001, 32p.

GOOGLE Earth. Imagens de Satélite. Disponível em: < www.googleearth.com>. Acesso em: 25 mai. 2008.

GRAVATAÍ. Prefeitura Municipal. História. Disponível em: $<$ http://www.gravatai.rs.gov.br/cidade/historia.php $>$. Acesso em 22 abr. 2010.

HENDRIKS, C.; GRAUS, W.; VAN BERGEN, F. Global carbon dioxide storage potential and costs. Relatório EEP-02001, EcofysTNO, Utrech, 71p. 2004.

LE TREUT, H.; SOMERVILLE, R.; CUBASCH, U.; DING, Y.; MAURITZEN, C.; MOKSSIT, A.; PETERSON T.; PRATHER, M. 2007. Historical Overview of Climate Change. In: Climate Change 2007: The Physical Science Basis. Contribution of Working Group I to the Fourth Assessment Report of the Intergovernmental Panel on Climate Change [Solomon, S., D. Qin, M. Manning, Z. Chen, M. Marquis, K.B. Averyt, M. Tignor and H.L. Miller (eds.)]. Cambridge University Press, Cambridge, United Kingdom and New York, NY, USA.

KETZER, J. M.; IGLESIAS, R. S.; EINLOFT, S.; DULLIUS, J. ; LIGABUE, R.; LIMA, V. Water-rock-CO2 interactions in saline aquifers aimed for carbon dioxide storage: Experimental and numerical modeling studies of the Rio Bonito Formation (Permian), southern Brazil. Applied Geochemistry, v. 24, p. 760767, 2009.

KETZER, J.M.M.; VILLWOCK, J.A.; CAPORALE, G.; ROCHA, L.H.S.; ROCKETT, G.; BRAUN, H.; GIRAFFA, L. 2007.

Opportunities for $\mathrm{CO}_{2}$ capture and geological storage in Brazil: 
ROCKETT, G.C e KETZER, J.M.M. Redes de dutos e transformações ...

The Carbmap Project. In: Annual Conference on Carbon

Capture \& Sequestration, 6, Pittsburgh, Pensilvânia. Resource Book. Pittsburgh.

LIMA, V.; EINLOFT, S.; KETZER, J. M.; JULLIEN, M.;

BILDSTEIN, O.; PETRONIN, J. CO2 Geological storage in saline aquifers: Paraná Basin caprock and reservoir chemical reactivity. Energy Procedia, v. 4, p. 5377-5384, 2011.

MACHADO, C.X.; KETZER, J.M.; ROCKETT, G.C.; CENTENO, C.I. 2010. Brazilian Atlas on Carbon Capture, Transport and Storage: developing methodology. In: Rio Oil \& Gas Expo and Conference, Anais..., 13-16 september (no prelo).

MORAES, Antonio Carlos Robert. Geografia: Pequena História Crítica. $17^{\mathrm{a}}$ ed. São Paulo: Editora Hicitec, 1999. 138p.

OWEN, Wilfred. Estratégia para os transportes. Tradução de David H. Fastings. São Paulo: Pioneira, 1975. 205p.

ROCKETT, G. C.; MACHADO, C. X.; KETZER, J.M.; CENTENO, C. The CARBMAP Project: Matching $\mathrm{CO}_{2}$ Sources and Geological Sinks in Brazil using Geographic Information System. Energy Procedia, v. 4, p. 2764-2771, 2011.

SANTOS, André Luís Bandeira dos. Faixa de dutos. [14 ago. 2008] Entrevistador: Gabriela Camboim Rockett. Canoas: Petrobras Transporte S.A. - Transpetro. Supervisor de manutenção de faixa de dutos - gerência Sul.

SANTOS, Milton. A natureza do espaço: técnica e tempo, razão e emoção. $4^{\mathrm{a}}$ ed. $4^{\mathrm{a}}$ reimpressão. São Paulo: Editora da Universidade de São Paulo, 2008. 392p. 
ROCKETT, G.C e KETZER, J.M.M. Redes de dutos e transformações ... SANTOS, Milton; SILVEIRA, Maria Laura. O Brasil: território e sociedade no início do Século XXI. São Paulo: Editora Record, 2001. 474p.

SCHIER, Raul Alfredo. Trajetórias do conceito de paisagem na geografia. Revista RA' E GA, Curitiba, n.8, p. 83-91, 2004.

Editora UFPR.

SOUSA, Marcos Timóteo Rodrigues de. Transporte dutoviário: a circulação de combustíveis em São Paulo (1990-2000). Caminhos da Geografia, Uberlândia, v.2, n.16, p. 6-13, 2005.

SUERTEGARAY, Dirce Maria Antunes. Espaço geográfico uno e múltiplo. In: SUERTEGARAY, Dirce Maria Antunes; BASSO, Luís Alberto; VERDUM, Roberto (org.). Ambiente e lugar no urbano: a grande Porto Alegre. Porto Alegre: Editora da Universidade/UFRGS, 2000. p. 13-34.

Recebido em outubro de 2011 Aceito em novembro de 2011 